\title{
ANÁLISE DE INDICADORES FINANCEIROS E DE ESTRUTURA DE CAPITAL DA EMPRESA GERDAU: comparativo dos anos de 2005 a 2014
}

Jocias Maier ZANATTA ${ }^{1}$

Ane Caroline de CARLI ${ }^{2}$

Vanise Raquel Scherer SCHONS ${ }^{3}$

\begin{abstract}
${ }^{1}$ Mestre em Desenvolvimento pela Universidade Regional do Noroeste do Estado do Rio Grande do Sul - UNIJUI, Professor da Sociedade Educacional Três de Maio - SETREM. josk85@hotmail.com

${ }^{2}$ Acadêmica do curso de Bacharelado em Administração da Sociedade Educacional Três de Maio - SETREM. karolaynedecarli@hotmail.com

${ }^{3}$ Acadêmica do curso de Bacharelado em Administração da Sociedade Educacional Três de Maio - SETREM. vaniseraquel@hotmail.com
\end{abstract}

Recebido em: 27/10/2016 - Aprovado em: 15/09/2017 - Disponibilizado em: 30/12/2017

\section{RESUMO}

O presente trabalho tem como objetivo analisar o desempenho da empresa Gerdau no período de 2005 a 2014, através do cálculo dos indicadores financeiros e de estrutura de capital. Através das demonstrações contábeis buscou-se responder a seguinte questão: como os indicadores obtidos por meio do balanço patrimonial podem ser utilizados na análise financeira e de estrutura de capital em uma companhia de capital aberto?Para a realização da pesquisa, utilizou-se o método de abordagem dedutivo, qualitativo e quantitativo; com procedimento descritivo e estudo de caso; e como técnicas de coleta e análise de dados, pesquisa documental e planilha eletrônica. No estudo, a partir das demonstrações contábeis, foram realizadas as análises horizontal e vertical, e calculados os indicadores financeiros e de estrutura de capital. Como resultados da pesquisa, conclui-se que os indicadores obtidos através do balanço patrimonial servem de parâmetro para a análise financeira e de estrutura de capital de uma companhia de capital aberto. A companhia apresenta tendência de queda nas dívidas de curto prazo, indicadores financeiros realistas e indicadores de estrutura de capital favoráveis.

Palavras-Chave: Administração financeira. Indicadores financeiros. Indicadores de estrutura de capital.

\section{ABSTRACT}

This study aims to analyze the company Gerdau's performance in the period 2005-2014, through the calculation of financial ratios and capital structure. Through the financial statements we sought to answer the following question: how the indicators obtained through the balance sheet can be used in financial analysis and capital structure in a publicly traded company? For the research, we used the method of deductive, quantitative and qualitative approach; with descriptive procedure and case study; and as collection techniques and data analysis, document research and spreadsheet. In the study, from the financial statements, there were horizontal and vertical analysis, and calculated the financial and capital structure indicators. As a result of the research, it was concluded that the indicators obtained from the balance sheet be parameter for financial analysis and capital structure of a public company.The company has downward trend in short-term debt, realistic financial indicators and favorable capital structure indicators.

Keywords: Financial management. Financial indicators. Capital structure indicators. 


\section{INTRODUÇÃO}

O atual cenário político e econômico de incertezas somado ao mercado competitivo e dinâmico no qual as organizações estão inseridas, exige que as empresas busquem eficiência na sua gestão financeira. Neste contexto, mensurar e acompanhar os indicadores financeiros e de estrutura de capital é imprescindível para conduzir o processo de tomada de decisões.

O cálculo e análise de indicadores financeiros e de estrutura de capital são uma das formas de avaliar o desempenho organizacional (FERRAES NETO, 2002), onde a análise destes indicadores não se resume a aplicação de uma fórmula, sendo de grande importânciaa sua interpretação (GITMAN, 2004).

$\mathrm{O}$ presente estudo tem o objetivo de analisar o desempenho da empresa Gerdau no período de 2005 a 2014, através do cálculo dos indicadores financeiros e de estrutura de capital.A pesquisa buscou avaliar as demonstrações contábeis da empresa Gerdau e responder ao seguinte questionamento: como os indicadores obtidos por meio do balanço patrimonial podem ser utilizados na análise financeira e de estrutura de capital em uma companhia de capital aberto?

Diante do exposto, justifica-se o atual estudo pela relevância da empresa Gerdau para a economia do Brasil, por ser uma companhia de capital aberto, líder no segmento de aços longos nas Américas e uma das principais fornecedoras de aços longos especiais do mundo (GERDAU, 2015).

Para tanto o presente artigo está estruturado em cinco partes, sendo que após a introdução, apresenta-se o referencial teórico sobre os assuntos abordados, tais como: administração financeira, análise horizontal e vertical, indicadores financeiros e indicadores de estrutura de capital. Em seguida, são descritos os métodos utilizados na pesquisa. Após, são apresentados, na forma de gráficos, quadros e comentários, os resultados e, por fim, as considerações finais do estudo.

\section{REFERENCIAL TEÓRICO}

\subsection{Administração financeira}

A administração financeira trata das tarefas dos administradores que gerenciam os assuntos financeiros das organizações de qualquer natureza, sejam financeiras ou não, públicas ou privadas, grandes ou pequenas, e com ou sem fins lucrativos (GITMAN, 2004).

$$
\text { Para Silva (2013) a administração }
$$
financeira é uma ciência que tem o objetivo de gerenciar o processo de captação de recursos e alocação de capital de forma eficiente. A necessidade de adaptação organizacional faz com que as empresas utilizem novas técnicas de administração financeira (CABRELLI, FERREIRA, 2007). 
Neste contexto de evolução, a administração financeira assume uma importância de maior amplitude, onde se envolve tanto com os desafios da escassez de recursos, quanto com a realidadeoperacional e de gestão das organizações (ASSAF NETO; LIMA, 2014).

\subsubsection{Análise Vertical e Horizontal}

A análise vertical busca avaliar a importância de cada conta em relação a demonstração contábil a que pertence (FANTI et al., 2016), através da análise da participação percentual dos elementos das demonstrações contábeis (PADOVEZE; BENEDITO, 2004). Assaf Neto (2012) complementa que dispondo de valores absolutos é possível mensurar a participação de cada conta no ativo, passivo ou na demonstração de resultados.

A análise horizontal tem o objetivo de verificar a evolução dos elementos patrimoniais ou de resultado em um período de tempo, sendo possível comparar contas ou grupo de contas em diferentes exercícios sociais (ASSAF NETO, 2012; FERREIRA, 2009). Para realizar esta comparação é necessário ter os dados de pelo menos dois exercícios sociais.

Assaf Neto (2002, p. 100), reforça a definição da análise horizontal:

“Análise horizontal é a comparação que se faz entre os valores de uma mesma conta ou grupo de contas, em diferentes exercícios sociais.
É basicamente um processo de análise temporal, desenvolvido por meio de inúmeros índices."(ASSAF NETO, 2002, p.100).

Para avaliar os dados das demonstrações contábeis é recomendado que as técnicas de análise horizontal e vertical sejam utilizadas em conjunto, de forma complementar (MATARAZZO, 2003).

\subsubsection{Indicadores financeiros}

Os indicadores financeiros tem $\mathrm{o}$ objetivo de demonstrar a capacidade de pagamento da organização, onde são expressos através de índices de liquidez, que devem ser analisados de forma conjunta e complementar.

$\mathrm{Na}$ análise financeira pode-se realizar a divisão em quatro indicadores básicos: liquidez imediata, liquidez corrente, liquidez seca e liquidez geral (SANVICENTE, 1987). Estes indicadores devem ser analisados na perspectiva de que quanto maior for o resultado obtido, maior será a capacidade de pagamento da organização.

Os índices de liquidez são aplicados para avaliar a capacidade de pagamento da empresa, isto é calcula se uma empresa tem capacidade para saldar seus compromissos em curto prazo, e também são importantes na avaliação do risco dos títulos de uma empresa (GITMAN, 2004). A seguir são apresentados os conceitos e fórmulas dos indicadores de liquidez, de acordo com Ribeiro (2014): 
Liquidez Imediata: Mede a capacidade de pagamento da empresa. É o mais conservador de todos, pois considera apenas as disponibilidades, ou seja, apenas as contas que possuem liquidez imediata. Desta forma, desconsidera do cálculo as demais contas do ativo circulante. A fórmula para o cálculo é apresentada a seguir:

Liquidez Imediata $=\frac{\text { Disponilbilidades }}{\text { Passivo Circulante }}$

\section{Liquidez Corrente: Reflete a} capacidade de pagamento da empresa em curto prazo, onde são confrontados os dados de todo o ativo circulante com as dívidas existentes á curto prazo. A fórmula para o cálculo é apresentada a seguir:

Liquidez Corrente $=\frac{\text { Ativo Circulante }}{\text { Passivo Circulante }}$

Liquidez Seca: Apresenta o poder de pagamento de dívidas de curto prazo da empresa. É semelhante à liquidez corrente, no entanto, neste caso se subtrai do ativo circulante o valor dos estoques por ser uma conta considerada de baixa liquidez. O resultado deste índice será invariavelmente menor que o de liquidez corrente. A fórmula para o cálculo é apresentada a seguir:

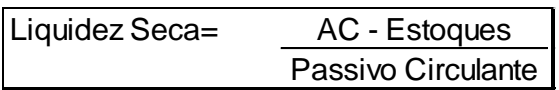

Liquidez Geral: Mede a capacidade de pagamento da empresa frente a totalidade de suas dívidas, neste caso é levado em consideração o ativo circulante, realizável a longo prazo, passivo circulante e exigível a longo prazo. A fórmula para o cálculo é apresentada a seguir:

Liquidez Geral $=\frac{A C+\text { Realizável } a \mathrm{LP}}{P C+\text { Exigivel } \mathrm{L} L \mathrm{P}}$

\subsubsection{Indicadores de estrutura de capital}

Os indicadores de estrutura de capital tem o objetivo de demonstrar a dependência da organização em relação a recursos de terceiros, e avaliam a composição e a aplicação de recursos (FANTI et al., 2016), sendo os indicadores básicos: participação de capital de terceiros, composição do endividamento e imobilização do patrimônio líquido (SANVICENTE, 1987).

Estes indicadores fornecem informações para o investidor ou administrador financeiro avaliar a relação entre capitais próprios e capitais de terceiros. O endividamento da organização indica o volume aplicado de recursos financeiros de terceiros (GITMAN, 2010), desta forma, evidencia a composição das origens de recursos investidos no patrimônio (RIBEIRO, 2014).

A seguir são apresentados os conceitos e fórmulas dos indicadores de estrutura de capital, de acordo com Ribeiro (2014): 


\section{Participação de Capital de Terceiros:}

Indica a dependência da empresa em relação a capital de terceiros, onde o parâmetro para análise é quanto menor melhor. A fórmula para o cálculo é apresentada a seguir:

$\begin{gathered}\text { Participação de Capital } \\ \text { de Terceiros }\end{gathered}$
de

\section{Composição do Endividamento:}

Indica em percentual quanto à empresa está comprometida com dívidas de curto prazo em relação às obrigações totais. Recomenda-se que o endividamento esteja concentrado no longo prazo. A fórmula para o cálculo é apresentada a seguir:

\begin{tabular}{|c|c|c|c|}
\hline Composição do & $=$ & Passivo Circulante & $\times 100$ \\
\hline Endividamento & & Capitais de Terceiros & \\
\hline
\end{tabular}

\section{Imobilização do Patrimônio Líquido:}

Indica que parcela do patrimônio líquido a empresa aplicou em ativos de natureza permanente. A fórmula para o cálculo é apresentada a seguir:

\begin{tabular}{|cc|}
\hline Imobilizações do \\
Patrimônio Liquido
\end{tabular}$\quad=\frac{\text { Ativo Permanente }}{\text { Patrimônio Liquido }} \times 100$

\section{METODOLOGIA}

A metodologia tem por finalidade estudar o caminho metodológico utilizado para alcançar os objetivos propostos pela pesquisa (LOVATO, 2013). Para a execução desta pesquisa utilizou-se a abordagem dedutiva, qualitativa e quantitativa; em relação aos procedimentos descritiva e estudo de caso; e quanto as técnicas de coleta e análise de dados, pesquisa documental e planilha eletrônica.

\subsection{Métodos de abordagens}

$\mathrm{Na}$ pesquisa utilizou-se o método dedutivo, onde através da revisão de literatura em livros e artigos científicos, foi possível esclarecer os principais conceitos acerca da temática do estudo. Foram explorados os conceitos referentes a administração financeira, indicadores financeiros e indicadores de estrutura de capital.

O estudo também contemplou a utilização da abordagem qualitativa, para a análise e interpretação dos dados. Neste caso, os dados se referem as publicações legais das demonstrações contábeis da empresa Gerdau do período de 2005 a 2014.

A abordagem quantitativa foi utilizada para trabalhar os dados numéricos, onde o estudo se caracterizou pelo rigor no tratamento dos dados para mensurar os indicadores financeiros e de estrutura de capital.

\subsection{Métodos de procedimentos}

No estudo, adotou-se o procedimento de estudo de caso, onde o objeto de análise foi uma única organização, com o objetivo de mensurar e analisar os indicadores financeiros e de estrutura de capital.

Através da pesquisa descritiva foi possível descrever os argumentos e ideias dos autores pesquisados em relação a temática do 
estudo, e através das notas explicativas das demonstrações contábeis elucidar o comportamento dos indicadores calculados.

\subsection{Técnicas}

\subsubsection{Técnica de coleta de dados}

Para a coleta de dados adotou-se a pesquisa documental, onde os dados foram extraídos do próprio site da organização objeto de estudo, a qual tem por obrigação legal divulgar seus demonstrativos contábeis pelo fato de se tratar de uma Sociedade Anônima S/A de capital aberto na BM\&Fbovespa. Foram coletados os demonstrativos contábeis e notas explicativas referentes ao período de 2005 a 2014.

\subsubsection{Técnica de análise de dados}

Como técnica de análise de dados utilizou-se a planilha eletrônica do Microsoft Excel $^{\circledR}$. Através desta ferramenta foi possível tabular os dados numéricos, realizar as análises horizontal e vertical, e calcular os indicadores financeiros e de estrutura de capital. Neste processo de análise dos dados, as notas explicativas das demonstrações contábeis foram fundamentais para avaliar o comportamento dos indicadores.

\section{ANÁLISE DOS RESULTADOS}

\subsection{Apresentação da empresa}

A Metalúrgica Gerdau S.A. é uma empresa brasileira, familiar, pertencente ao Grupo Gerdau, que atua no setor de metalurgia, manufatura de pregos e produtos metalúrgicos em geral, bem como na exploração comercial de produtos de ferro, aço e outros metais, e de material de construção em geral.

O grupo Gerdau começou suas operações em 1901 com a fábrica de pregos Pontas de Paris localizada em Porto Alegre (RS). Em 1969 ainda com cede executiva na capital gaúcha, o nome da companhia foi alterado para Metalúrgica Gerdau S.A.

A empresa possuía como objetivo suprir a escassez de matéria prima, e foi a partir disso que passou a investir também no setor siderúrgico. O foco principal no início de suas atividades foi de aumentar a sua capacidade de produção, podendo assim suprir a demanda do mercado nacional, e á partir da produção em grande escala competir no mercado internacional.

A empresa está presente em 14 países, sendo eles: Argentina, Brasil, Canadá, Chile, Colômbia, Espanha, Estados Unidos, México, Índia, Peru, República Dominicana, Uruguai e Venezuela, as quais somam uma capacidade instalada superior a 25 milhões de toneladas de aço. 
No Brasil, possui operações em quase todos os Estados, onde produz aços longos comuns, especiais e planos. Os produtos da Gerdau são manufaturados com uma ampla gama de especificações, com a finalidade de satisfazer um diversificado grupo de consumidores. Os três principais mercados em que a companhia opera sãoos setores de construção civil, indústria e agropecuária, sendo os dois primeiros responsáveis pelo maior volume de vendas da companhia.

A Gerdau possui seu capital aberto na bolsa de valores, tendo nível 1 de governança corporativa e mantém o controle acionário com mais de $76 \%$ das ações ordinárias. Em relação à governança corporativa, a companhia possui um conselho de administração bastante atuante, presidido por Jorge Gerdau Johannpeter. Dos nove membros do Conselho, seis fazem parte da família. Em relação à diretoria da empresa, André Bier Gerdau Johannpeter é o diretor presidente, com André Pires como diretor financeiro.
O Conselho de Administração é o órgão encarregado de estabelecer as estratégias do Grupo Gerdau e de acompanhar a execução das políticas adotadas. A estrutura de governança da Gerdau está representada na Figura 1.

Figura 1 -Estrutura de governança corporativada Gerdau Fonte: Gerdau, 2015.

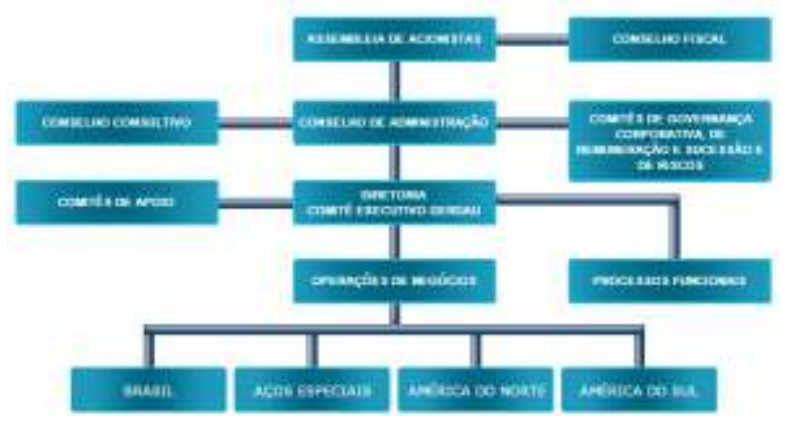

\subsection{Análise vertical e horizontal}

A análise vertical tem o objetivo de mostrar a representatividade de cada conta em relação ao valor total do balanço patrimonial. Para facilitar a compreensão se optou em apresentar as análises das contas do ativo e passivo de forma separada. O Quadro 1 apresenta a análise vertical do ativo.

Quadro 1 -Análise vertical do ativo (valores em \%)

\begin{tabular}{|l|c|c|c|c|c|c|c|c|c|c|}
\hline & $\mathbf{2 0 0 5}$ & $\mathbf{2 0 0 6}$ & $\mathbf{2 0 0 7}$ & $\mathbf{2 0 0 8}$ & $\mathbf{2 0 0 9}$ & $\mathbf{2 0 1 0}$ & $\mathbf{2 0 1 1}$ & $\mathbf{2 0 1 2}$ & $\mathbf{2 0 1 3}$ & $\mathbf{2 0 1 4}$ \\
\hline Ativo Circulante & 14,44 & 8,96 & 2,58 & 8,70 & 7,25 & 3,25 & 7,44 & 2,96 & 1,93 & 4,36 \\
\hline Realizável a L.P. & 1,46 & 3,18 & 6,93 & 5,44 & 0,74 & 3,62 & 1,59 & 1,54 & 1,50 & 2,11 \\
\hline Permanente & 84,10 & 87,86 & 91,11 & 85,85 & 92,01 & 93,13 & 90,97 & 95,50 & 96,57 & 93,64 \\
\hline
\end{tabular}

Fonte: Elaborado pelos autores, 2015.

Os dados mostram que as contas do ativo circulante tiveram uma redução de $69,80 \%$ no período avaliado (2005-2014), no entanto, este número não reflete a realidade, pois as disponibilidades e o montante total do ativo tiveram significativo aumento, tendo um 
panorama positivo. Isso reforça a importância de não analisar os indicadores de forma isolada, e sim de forma conjunta.
O Quadro 2 apresenta a análise vertical do passivo.

Quadro 2 -Análise vertical do passivo (valores em \%)

\begin{tabular}{|l|c|c|c|c|c|c|c|c|c|c|}
\hline & $\mathbf{2 0 0 5}$ & $\mathbf{2 0 0 6}$ & $\mathbf{2 0 0 7}$ & $\mathbf{2 0 0 8}$ & $\mathbf{2 0 0 9}$ & $\mathbf{2 0 1 0}$ & $\mathbf{2 0 1 1}$ & $\mathbf{2 0 1 2}$ & $\mathbf{2 0 1 3}$ & $\mathbf{2 0 1 4}$ \\
\hline Passivo Circulante & 2,86 & 3,15 & 3,70 & 2,33 & 3,32 & 1,92 & 2,33 & 2,38 & 1,60 & 0,82 \\
\hline Passivo Exigível a L.P. & 21,51 & 16,36 & 17,56 & 11,06 & 11,89 & 15,54 & 14,21 & 11,46 & 14,80 & 15,80 \\
\hline Patrimônio Líquido & 75,63 & 80,48 & 78,74 & 86,61 & 84,79 & 82,54 & 83,46 & 86,17 & 83,60 & 83,38 \\
\hline
\end{tabular}

Fonte: Elaborado pelos autores, 2015.

Os números mostram que no período avaliado (2005-2014) a composição do passivo é favorável, com tendência de queda nas dívidas de curto prazo, manutenção das dívidas de longo prazo, e aumento do percentual do patrimônio líquido.

A análise horizontal demonstra o comportamento das contas do balanço patrimonial entre determinado período de tempo. No estudo foram analisados os dados anuais do período de 2005 a 2014, e para facilitar o entendimento os resultados serão apresentados através de quadros e gráficos.

O Quadro 3 apresenta a análise horizontal do ativo:

Quadro 3 -Análise horizontal do ativo (valores em \%)

\begin{tabular}{|l|c|c|c|c|c|c|c|c|c|}
\hline & $\mathbf{2 0 0 5 / 2 0 0 6}$ & $\mathbf{2 0 0 6 / 2 0 0 7}$ & $\mathbf{2 0 0 7 / 2 0 0 8}$ & $\mathbf{2 0 0 8 / 2 0 0 9}$ & $\mathbf{2 0 0 9 / 2 0 1 0}$ & $\mathbf{2 0 1 0 / 2 0 1 1}$ & $\mathbf{2 0 1 1 / 2 0 1 2}$ & $\mathbf{2 0 1 2 / 2 0 1 3}$ & $\mathbf{2 0 1 3 / 2 0 1 4}$ \\
\hline Total Ativo Circulante & $-27,75$ & $-66,31$ & 382,75 & $-21,35$ & $-45,98$ & 190,67 & $-58,07$ & $-25,00$ & 140,29 \\
\hline Total Do Realizável a Longo Prazo & 154,48 & 132,50 & 23,24 & $-87,16$ & 489,25 & $-44,35$ & 2,52 & 11,53 & 42,11 \\
\hline Total do Permanente & 21,62 & 21,48 & 34,73 & 1,20 & 21,93 & 24,04 & 10,82 & 16,06 & 3,19 \\
\hline Total do Ativo & 16,42 & 17,15 & 42,98 & $-5,57$ & 20,46 & 26,98 & 5,57 & 14,77 & 6,42 \\
\hline
\end{tabular}

Fonte: Elaborado pelos autores, 2015.

Através dos dados se visualiza grande variação nas contas do ativo, em parte, está instabilidade é causada pela influência do

O Quadro 4 apresenta a análise

horizontal do passivo: câmbio, pelo fato da companhia atuar em diversos países através de exportação e importação. 
Quadro 4 - Análise horizontal do passivo (valores em \%)

\begin{tabular}{|l|c|c|c|c|c|c|c|c|c|}
\hline & $\mathbf{2 0 0 5 / 2 0 0 6}$ & $\mathbf{2 0 0 6 / 2 0 0 7}$ & $\mathbf{2 0 0 7 / 2 0 0 8}$ & $\mathbf{2 0 0 8 / 2 0 0 9}$ & $\mathbf{2 0 0 9 / 2 0 1 0}$ & $\mathbf{2 0 1 0 / 2 0 1 1}$ & $\mathbf{2 0 1 1 / 2 0 1 2}$ & $\mathbf{2 0 1 2 / 2 0 1 3}$ & $\mathbf{2 0 1 3 / 2 0 1 4}$ \\
\hline Total Passivo Circulante & $\mathbf{2 8 , 1 9}$ & 37,68 & $-9,92$ & 34,34 & $-30,50$ & 54,56 & 7,58 & $-22,59$ & $-45,36$ \\
\hline Total do Exigível a Longo Prazo & $-11,44$ & 25,68 & $-9,94$ & 1,54 & 57,45 & 16,10 & $-14,90$ & 48,22 & 13,62 \\
\hline Total do patrimônio liquido & 23,90 & 14,61 & 57,26 & $-7,55$ & 17,27 & 28,39 & 8,99 & 11,35 & 6,14 \\
\hline Total do Passivo & 16,42 & 17,15 & 42,98 & $-5,57$ & 20,46 & 26,98 & 5,57 & 14,77 & 6,42 \\
\hline
\end{tabular}

Fonte: Elaborado pelos autores, 2015.

A análise horizontal do passivo traz um panorama favorável, visto que, as dívidas de curto prazo tiveram redução nos últimos anos, devido a companhia buscar ampliar os financiamentos de longo prazo, com tendência de melhores taxas de juros. O total do passivo no período analisado (2005-2014) teve significativa redução de 60,90\% .

\subsection{Análise de indicadores financeiros}

Os indicadores financeiros tem $\mathrm{o}$ objetivo de demonstrar a capacidade de pagamento da organização. Em vista disso, o Quadro 5 apresenta os principais indicadores de liquidez calculados no período analisado (20052014).

Quadro 5: Indicadores financeiros

\begin{tabular}{|l|c|c|c|c|c|c|c|c|c|c|}
\hline & $\mathbf{2 0 0 5}$ & $\mathbf{2 0 0 6}$ & $\mathbf{2 0 0 7}$ & $\mathbf{2 0 0 8}$ & $\mathbf{2 0 0 9}$ & $\mathbf{2 0 1 0}$ & $\mathbf{2 0 1 1}$ & $\mathbf{2 0 1 2}$ & $\mathbf{2 0 1 3}$ & $\mathbf{2 0 1 4}$ \\
\hline Liquidez Imediata & 4,19 & 0,00 & 0,00 & 0,00 & 0,00 & 0,11 & 0,17 & 0,13 & 0,16 & 0,25 \\
\hline Liquidez Corrente & 5,05 & 2,84 & 0,70 & 3,73 & 2,18 & 1,70 & 3,19 & 1,24 & 1,21 & 5,30 \\
\hline Liquidez Seca & 5,05 & 2,84 & 0,70 & 3,73 & 2,18 & 1,08 & 2,73 & 0,84 & 0,69 & 4,47 \\
\hline Liquidez Geral & 0,65 & 0,62 & 0,42 & 1,06 & 0,53 & 0,39 & 0,55 & 0,33 & 0,21 & 0,38 \\
\hline
\end{tabular}

Fonte: Elaborado pelos autores, 2015.

A liquidez imediata no período de 2006 a 2009 esteve em queda, pois neste período o aumento das disponibilidadesnão acompanhou as dívidas de curto prazo, que foram de $18,02 \%$ e $66,60 \%$, respectivamente. Á partir do ano de 2010 este indicador passou a aumentar gradativamente em razão da redução do passivo circulante.

Os dados referentes aos indicadores de liquidez corrente e liquidez seca tem comportamento próximo, devido aos valores de estoque serem baixos e ter sido alterada a forma de contabilização a partir do ano de 2010. Estes indicadores estão com valores favoráveis, tendo como parâmetro acima de 1,00.

A liquidez geral da empresa não apresenta números absolutos favoráveis, tendo como parâmetro acima de 1,00. No entanto, ao considerar que a companhia tem buscado reduzir as dívidas de curto prazo e optar por financiamentos a longo prazo, tem-se um cenário realista. 


\subsection{Análise de indicadores de estrutura de capital}

Os indicadores de estrutura de capital tem o objetivo de demonstrar a dependência da organização em relação a recursos de terceiros.
Em vista disso, o Quadro 6 apresenta os principais indicadores de estrutura de capital calculados no período analisado (2005-2014).

Quadro 6: Indicadores de estrutura de capital (valores em \%)

\begin{tabular}{|c|c|c|c|c|c|c|c|c|c|c|}
\hline & 2005 & 2006 & 2007 & 2008 & 2009 & 2010 & 2011 & 2012 & 2013 & 2014 \\
\hline Participação de Capitais de Terceiros & 32,23 & 24,25 & 27,00 & 15,46 & 17,94 & 21,15 & 19,82 & 16,05 & 19,62 & 19,93 \\
\hline Composição do Endividamento & 11,74 & 16,15 & 17,42 & 82,58 & 21,82 & 10,97 & 14,09 & 17,18 & 9,77 & 4,95 \\
\hline Imobilização do Patrimônio Líquido & 111,21 & 109,16 & 115,71 & 99,13 & 108,52 & 112,83 & 109,01 & 110,84 & 115,52 & 112,31 \\
\hline
\end{tabular}

Fonte: Elaborado pelos autores, 2015.

O indicador de participação de capitais de terceiros teve redução de $38,16 \%$ no período analisado (2005-2014), no entanto nos últimos dois anos se manteve estável, o que merece atenção da empresa, devido ao parâmetro de análise do indicador ser de quanto menor melhor.

A composição do endividamento reflete a política de troca de financiamentos de curto prazo por modalidades de longo prazo, que representou no período analisado (2005-2014) redução de $57,83 \%$, o que caracteriza um cenário positivo. $\mathrm{O}$ indicador de imobilização do patrimônio líquido, apesar de estável, necessita atenção para não ampliar a necessidade de capital de terceiros.

\section{CONSIDERAÇÕES FINAIS}

As organizações, independente de seu porte, estão inseridas em um mercado competitivo e dinâmico, que atrelado ao atual cenário econômico e político de incertezas, exige eficiência na gestão financeira. Em se tratando de uma companhia de capital aberto e com grande importância para o país, a gestão financeira se torna complexa.

O presente estudo teve como objetivo analisar o desempenho da empresa Gerdau no período de 2005 a 2014 através do cálculo de indicadores financeiros e de estrutura de capital. Os dados para a realização da pesquisa foram buscados nas publicações legais das demonstrações contábeis da empresa. O objetivo foi atingido através da apresentação da análise horizontal e vertical, cálculo dos indicadores financeiros e indicadores de estrutura de capital.

A pesquisa buscouresponder ao seguinte questionamento: como os indicadores obtidos por meio do balanço patrimonial podem ser utilizados na análise financeira e de estrutura de capital em uma companhia de capital aberto?O problema foi elucidado através dos cálculos e análises realizadas, onde se compreendeu que a análise e interpretação dos 
indicadores resultantes do balanço patrimonial e das notas explicativas são parâmetros para avaliar o desempenho de uma companhia de capital aberto.

$\mathrm{Na}$ análise horizontal e vertical do balanço patrimonial observou-se em relação a sua composição, redução das contas do ativo circulante e nova distribuição das contas do passivo; já em relação à variação no período analisado (2005-2014), houve significativa variação no ativo circulante, devido à influência do câmbio, e redução das dívidas de curto prazo.

Quanto aos indicadores financeiros, a liquidez corrente e liquidez seca apresentam-se com resultados favoráveis, enquanto a liquidez imediata e a liquidez geral estão com números desfavoráveis, porem dentro de um cenário realista. Os indicadores de estrutura de capital são favoráveis, onde houve no período analisado (2005-2014) redução na dependência de capital de terceiros, no entanto, apesar de estável, o indicador de imobilização do patrimônio líquido merece atenção.

A organização objeto do estudo demonstrou possuir uma gestão financeira eficiente em relação aos indicadores calculados no período analisado (2005-2014), tendo um bom desempenho dos indicadores financeiros e de estrutura de capital. Para estudos futuros, sugere-se realizar estudos sob a ótica de outros indicadores e em diferentes exercícios sociais.

\section{REFERÊNCIAS}

ASSAF NETO, Alexandre; LIMA, Fabiano Guasti.2014. Fundamentos de Administração Financeira. 2 ed. São Paulo: Editora Atlas. ISBN: 9788522488001

ASSAF NETO, Alexandre. 2012. Estrutura e análise de balanços: um enfoque econômicofinanceiro. 10 ed. São Paulo: Atlas. ISBN: 9788522467860

Alexandre. 2012. Estrutura e análise de balanços: um enfoque econômicofinanceiro. 10 ed. São Paulo: Atlas. ISBN: 9788522467860

CABRELLI, Fantini Lígia; FERREIRA, Ademilson. 2007. Contabilidade gerencial como ferramenta no processo de tomada de decisão. Revista cientifica eletrônica de ciências contábeis. Ano V, n.9.ISSN: 16793870 .

DALFOVO, Michael Samir. et al. 2008. Métodos quantitativos e qualitativos: um resgate teórico. Revista Interdisciplinar Científica Aplicada. v. 2. n. 4. pp. 01-13. Blumenau. ISSN 1980-7031.

FANTI, L. D.; HRENECHEN, J. E.; MIRANDA, J. M.; SILVA, R. N.; REIS, R. A. D. 2016. Análise dos Principais Indicadores Contábeis e Financeiros: um Estudo de Caso sobre a Vale S/A nos Anos de 2011 e 2012. Desafio Online, v. 1, n. 1, p. 100-116. Campo Grande. ISSN: 2317-949x

FERRAES NETO, F. A relação da logística com a administração financeira e seus impactos nos índices financeiros de uma organização. 2002. Revista FAE, v. 5, n. 3, pp. 41-49, set./dez. Curitiba. ISSN: 1516-1234

FERREIRA, R. J. 2009. Análise das Demonstrações Financeiras. Belo Horizonte: Editora Ferreira. ISBN: 9788578421373 
GERDAU. 2015. Estrutura de Governança

Corporativa. Acessado em: 01/12/2015.

Disponível em:

http://ri.gerdau.com/static/ptb/estrutura-

governanca-corporativa.asp?idioma $=$ ptb.

GIL, Antônio Carlos. 2002. Como elaborar

projetos de pesquisa. 4. ed. São Paulo: Atlas.

ISBN: 85-224-3169-8

GITMAN, Lawrence J. 2010. Princípios de administração financeira. 12 ed. São Paulo:

Pearson. ISBN: 9788576053323

Lawrence J. 2004. Princípios de

administração financeira. São Paulo: Pearson.

ISBN: 9788588639126

Lawrence J. 1997. Princípios De

Administração Financeira. São Paulo: Harbra. ISBN: 9788588639126

LOVATO, Adalberto. 2013. Metodologia da

Pesquisa. Três de Maio: Setrem. ISBN:

9788599020050.

MATARAZZO, D. C. 2003. Análise

Financeira de Balanço. São Paulo: Editora

ATLAS. ISBN: 9788522456925

PADOVESE, C.L.; BENEDITO, G. C. de. 2004.Análise das Demonstrações

Financeiras. SãoPaulo: Pioneira Thomson Learning. ISBN: 9788522110704

RIBEIRO, Osni Moura. 2014. Estrutura e análise de balanços. 11 ed. São Paulo: Saraiva. ISBN: 9788502621862

RIBEIRO, Mayara de Oliveira; BOLIGON, Juliana Rüdell. 2009. Análise por meio de índices financeiros e econômicos: um estudo de caso em uma empresa de médio porte. Disciplinarum Scientia. Série: ciências sociais aplicadas. v. 5. n. 1. pp. 15-34. Santa Maria.

ISBN: 1981-5778
SANVICENTE, Antonio Zoratto. 1987.

Administração Financeira. São Paulo: Atlas. ISBN: 85-224-0221-3

SILVA, Bráulio Wilker. 2013. Objetivos da Administração Financeira. Acessado em: 02/11/2015. Disponível em:http://www.administradores.com.br/artigos/ economia-e-financas/objetivos-daadministracao-financeira/69169/. 